Удк $676.014 ; 577.152 .37$

\title{
ХАРАКТЕРИСТИКА СКОПА, ОБРАЗУЮЩЕГОСЯ ПРИ ЛОКАЛЬНОЙ ОЧИСТКЕ ВОЛОКНОСОДЕРЖАЩИХ СТОЧНЫХ ВОД
}

\author{
() Е.В. Новожилов", Д.Г. Чухчин, Е.В. Белых, П.В. Поротова, Е.А. Варакин, И.В. Тышкунова \\ Северный (Арктический) федеральный университет им. М.В. Ломоносова, \\ Набережная Северной Двины, 17, Архангельск, 163002 (Россия), \\ e-mail: biotech@agtu.ru
}

\begin{abstract}
Изучены состав и свойства скопа, полученного при очистке сточных вод бумажной фабрики методом флотации, представлены характеристики выделенных волокон скопа и веществ фильтратов, показана возможность улучшения обезвоживающей способности скопа путем его ферментативной обработки, оценено влияние добавления скопа на прочность отливок бумаги.

Ключевые слова: скоп, волокно, флотация, фракционирование, электронная микроскопия, обезвоживающая способность, целлюлаза.

Работа выполнена на оборудовании Центра коллективного пользования научньм оборудованием «Арктика» (Северный (Арктический) федеральный университет имени М.В. Ломоносова) при финансовой поддержке Минобрнауки России.
\end{abstract}

\section{Введение}

Мировые тенденции производства бумаги и картона характеризуются созданием и развитием систем локальной очистки оборотных вод для снижения потерь волокна и уменьшения сброса загрязнений на очистные сооружения [1]. Для улавливания волокна из оборотных и сточных вод нашел применение процесс флотации. Отделяемое при этом волокно (скоп) может быть возвращено в основной цикл производства. Недостаток данной технологии заключается в том, что в составе скопа наряду с качественным волокном содержится много очень мелких волокон, обрывков волокон, которые обладают большой водоудерживающей способностью. В результате этого скоп имеет высокую степень помола (до $80{ }^{\circ} Ш Р$ ) и отличается исключительно плохой обезвоживаемостью.

Новожилов Евгений Всеволодович - заведующий кафедрой биотехнологии и биотехнических систем, доктор технических наук, профессор, e-mail: e.novozhilov@narfu.ru

Чухчин Дмитрий Германович - доцент кафедры биотехнологии и биотехнических систем, кандидат технических наук, e-mail: dimatsch@ mail.ru

Бельх Екатерина Витальевна - аспирант кафедры биотехнологии и биотехнических систем, e-mail: belyhekaterina@mail.ru

Поротова Полина Владимировна - аспирант кафедры биотехнологии и биотехнических систем, e-mail: biotech@narfu.ru

Варакин Евгений Александрович - аспирант кафедры биотехнологии и биотехнических систем,

e-mail: varakin.ev@yandex.ru

Тышкунова Ирина Владимировна - аспирант кафедры биотехнологии и биотехнических систем, e-mail: biotech@narfu.ru
Добавление скопа в композицию бумаги и картона вызывает ряд затруднений: замедление водооддачи бумажной массы, снижение прочности бумажного листа во влажном состоянии, увеличение расхода пара в сушильной части и снижение производительности бумагоделательных машин (БДМ). По этим причинам некоторые предприятия уже отделенное волокно сбрасывают на очистные сооружения, существенно увеличивая общее количество отходов, вывозимых на свалки.

Состав скопа определяется видом бумаги и картона, он может меняться в зависимости от композиции бумажной массы. В большей степени изучен скоп, образующийся при переработке вторичного волокна [1]. Недостаточно данных о скопе, полученном при выработке продукции из первичных полуфабрикатов.

\footnotetext{
* Автор, с которым следует вести переписку.
} 
Цель работы - оценить состав и свойства этого вида скопа, дать характеристику волокна, уловленного методом флотации, исследовать возможность ферментативной модификации скопа и его дальнейшего применения.

\section{Экспериментальная часть}

В экспериментах были использованы пробы скопа, уловленного при очистке методом флотации сточных вод картонной фабрики ЦБК. Основными компонентами бумажной массы являются сульфатная хвойная небеленая целлюлоза и нейтрально-сульфитная полуцеллюлоза (НСПЦ), кроме того, к ним в небольшом количестве добавляют отходы производства сульфатной лиственной беленой целлюлозы. Товарной продукцией фабрики являются тарный картон и бумага для гофрирования (флютинг).

Суспензия скопа имеет температуру около $30^{\circ} \mathrm{C}$, значение $\mathrm{pH} 7,0-7,2$. Концентрация волокна в пробах скопа находится в пределах 1,3-1,5\%, степень помола составляет $73-76^{\circ}$ ШР. Характеристики и фракционный состав волокон сульфатной целлюлозы, НСПЦ и скопа определяли на приборах FQA и Morfi Compact (Франция). Способность к обезвоживанию контролировали по скорости фильтрования суспензии волокна на бумажном фильтре под вакуумом. Количество осадка на бумажном фильтре определяли после его высушивания до воздушно-сухого состояния. Для ряда исследований были получены пробы фильтратов путем отделения волокна двумя методами: фильтрованием на бумажном фильтре и на металлической сетке.

Исследование суспензии скопа, выделенных из него волокон и сухих веществ, растворенных в фильтрате, проводили с помощью сканирующего электронного микроскопа ZEISS «SIGMA VP» (детекторы InLens, SE2, ускоряющее напряжение 2 и 20 кB). Пробы сушили методом лиофильной сушки на установке Labconco (FreeZone 2,5L). Для улучшения качества снимков образцы напыляли слоем золотопалладиевой смеси толщиной 5 нм с помощью напылительной установки Q150T ES (Quorum).

Для ферментативной обработки использовали коммерческий препарат Fiber Care D компании Novozymes A/S (Дания). Основные характеристики целлюлазы Fiber Care D: активность - 9800 ECU/г, эндоглюканазная активность по карбоксиметилцеллюлозе - 273 ед/г, оптимальный диапазон действия по $\mathrm{pH}$ - 6-9. Обработку ферментом суспензии скопа и фильтратов проводили в термостате при температуре $35^{\circ} \mathrm{C}$ в течение 2 ч с расходом фермента 1,0 и 3,0 кг/т волокна. Значение $\mathrm{pH}$ массы находилось в пределах 7,07,2. После обработки пробы охлаждали, фильтровали на бумажном фильтре под вакуумом с контролем продолжительности обезвоживания и определяли выход остатка.

Готовили отливки из смеси небеленой сульфатной хвойной целлюлозы и скопа. Скоп подвергали ферментативной обработке расходом фермента 1,0 и 3,0 кг/т волокна, в контроле фермент не добавляли. Долю скопа в композиции массы задавали в количестве 5 и $10 \%$ от волокна. По стандартным методикам определяли показатели механической прочности: для отливок массой $75 \mathrm{~m}^{2} / \Gamma$ - разрывную длину и сопротивление продавливанию; для отливок массой $125 \mathrm{~m}^{2} / \Gamma$ - разрушающее усилие при сжатии кольца (RCT) и сопротивление сжатию короткого участка образца (SCT).

\section{Обсуждение результатов}

В промышленных условиях подготовка волокнистых полуфабрикатов для изготовления бумаги и картона происходит в виде суспензий волокон в водной фазе. Волокна в суспензии окружены оборотной водой, которая многократно используется для разбавления массы. Волокно накапливается в оборотной воде из-за его промоев на фильтрах и неполного удержания на сетке БДМ. При анализе скопа в условиях производства состав по волокну находился в пределах: сульфатная хвойная небеленая целлюлоза $29-48 \%$, НСПЦ - 50-69\%, сульфатная лиственная беленая целлюлоза - 2-5\%. Волокно скопа, полностью отделенное от компонентов оборотной воды, имеет такую же степень помола, как и неразмолотые исходные полуфабрикаты (табл. 1). Средние значения длины и ширины волокон скопа соответствуют усредненным значениям для композиции такого состава. Число каппа волокон скопа определяется соотношением в композиции бумажной массы волокон первичных полуфабрикатов.

Фракционный состав волокон скопа также соответствует их соотношению в композиции бумажной массы из первичных полуфабрикатов. Преобладают фракции коротких и средних волокон, доля волокон длиной более 1,6 мм всего около 15\% (табл. 2). Так как пробы для анализа взяты из технологических потоков, содержание фракции волокон менее 0,2 мм в образцах сульфатной хвойной целлюлозы и лиственной НСПЦ практически одинаково - сказалось разбавление суспензии оборотной водой. 
Таблица 1. Характеристики волокон первичных полуфабрикатов и скопа

\begin{tabular}{l|c|c|c|c}
\hline \multicolumn{1}{c|}{ Проба скопа } & $\begin{array}{c}\text { Степень } \\
\text { помола, }{ }^{\circ} \text { ШР }\end{array}$ & $\begin{array}{c}\text { Число } \\
\text { Каппа }\end{array}$ & $\begin{array}{c}\text { Средневзвешенная } \\
\text { длина волокна, мм }\end{array}$ & $\begin{array}{c}\text { Средняя ширина } \\
\text { волокна, мкм }\end{array}$ \\
\hline Сульфатная небеленая целлюлоза & $14-15$ & $51-53$ & $2,32-2,35$ & $35,6-38,7$ \\
Нейтрально-сульфитная полуцеллюлоза & $12-14$ & $110-120$ & $1,17-1,33$ & $31,3-38,6$ \\
Волокно, выделенное из скопа & $12-13$ & $71-100$ & $1,75-1,80$ & $33,4-35,3$ \\
\hline
\end{tabular}

Таблица 2. Фракционный состав волокон целлюлозы, полуцеллюлозы и скопа

\begin{tabular}{l|c|c|c|c|c|c}
\hline \multirow{2}{*}{ Вид волокна } & \multicolumn{7}{c}{ Массовая доля фракций волокон, \% } \\
\cline { 2 - 7 } & $0,1-0,2$ мм & $0,2-0,6$ мм & $0,6-1,6$ мм & $1,6-2,5$ мм & $2,5-4,5$ мм & $>4,5$ мм \\
\hline Сульфатная небеленая целлюлоза & 12,5 & 18,7 & 23,5 & 27,1 & 18,1 & 0,1 \\
Нейтрально-сульфитная & 11,7 & 20,1 & 60,5 & 6,0 & 1,7 & - \\
полуцеллюлоза & 17,4 & 21,1 & 45,5 & 8,6 & 7,3 & 0,1 \\
Скоп I (суспензия с флотатора) & 20,8 & 20,2 & 42,1 & 8,3 & 8,3 & 0,3 \\
Скоп II (суспензия с флотатора) & \multicolumn{7}{c}{} \\
\hline
\end{tabular}

При рецикле оборотной воды в ней возрастает количество мелких волокон, которые проходят сквозь сетки промывных фильтров и не удерживаются влажным полотном бумажной массы на сетке БДМ. В пробах скопа содержание фракции волокон длиной меньше 0,6 мм достигает 38-41\%. Наряду с этой фракцией накапливаются и другие компоненты, имеющие небольшие размеры относительно основной части волокон: фрагменты и обрывки волокон и сосудов, паренхимные клетки сердцевинных лучей. В оборотных водах содержатся также остатки крахмального связующего, различные химикаты, предназначенные для улучшения качества бумаги.

При очистке методом флотации сточных вод картонно-бумажного производства основная масса оборотной воды отделяется от фракции волокон и далее выводится из технологического цикла и направляется на очистные сооружения предприятия. Начальная концентрация волокна в оборотной воде низкая, соответственно степень сгущения волокна также невысокая. В массе после флотации (скопе) еще остается значительное количество оборотной воды с содержащимися в ней коллоидными и растворенными веществами. В результате степень помола скопа оказывается очень высокой - 73-76 ШР. При сгущении суспензии фильтрованием на сетке по мере удаления оборотной воды способность скопа к обезвоживанию улучшалась: при концентрации волокна $11,2 \%$ степень помола составляла 63 ШР, а при концентрации волокна $20,2 \%$ она снижалась до $29^{\circ}$ ШР. Это свидетельствует о том, что основной эффект на замедление обезвоживания скопа оказывают фракция мелочи и вещества, содержащиеся в водной среде.

Одна из проб скопа методом фильтрации на металлической сетке была дополнительно разделена на фракцию волокна и фильтрат. Отделенное таким образом волокно, судя по среднему значению ширины, было сильно набухшим (табл. 3).

Фракция волокна содержала много мелочи и коллоидных веществ и соответственно имела высокую степень помола. Мелочь (fines) играет важную роль в процессе производства бумаги, оказывает большое влияние на обезвоживание и формование влажного полотна бумаги и показатели прочности. Первичная мелочь присутствует в массе уже после варки, она представлена главным образом паренхимными клетками сердцевинных лучей [2]. При размоле целлюлозы идет фибриллирование волокон, при этом часть фибриллированного материала полностью отделяется от поверхности волокна, в результате в суспензии массы накапливается вторичная мелочь. Общее количество первичной и вторичной мелочи для сульфатной целлюлозы может достигать 2,4-3,0\% [2]. Оба вида мелочи имеют более высокую степень набухания и более высокую водоудерживающую способность, чем волокна. При добавлении вторичной мелочи улучшаются показатели механической прочности за счет образования дополнительных связей между волокнами [2].

Таблица 3. Характеристики волокон скопа и веществ фильтрата

\begin{tabular}{l|c|c|c|c|c}
\hline \multicolumn{1}{c|}{ Проба скопа } & $\begin{array}{c}\text { Концентрация, } \\
\%\end{array}$ & $\begin{array}{c}\text { Степень } \\
\text { помола, }{ }^{\circ} \text { ШР }\end{array}$ & $\begin{array}{c}\text { Средневзвешенная } \\
\text { длина волокна, мм }\end{array}$ & $\begin{array}{c}\text { Средняя ширина } \\
\text { волокна, мкм }\end{array}$ & $\begin{array}{c}\text { Количество } \\
\text { мелочи, процент } \\
\text { от числа волокон }\end{array}$ \\
\hline Скоп (суспензия) & 1,45 & 77 & 1,22 & 29,8 & 92,6 \\
Отделенное волокно & 17,1 & 77 & 1,21 & 38,4 & 81,2 \\
Вещества фильтрата & 0,28 & - & 0,33 & 28,6 & 99,5 \\
\hline
\end{tabular}


Фракционный состав волокон в суспензии скопа и отделенного волокна, определенный на приборе Morfi Compact (Франция), практически аналогичен. В веществах фильтрата представлены фракции обрывков волокон и очень коротких волокон, доля мелочи и волокон длиной менее 0,6 мм составляет более $91 \%$ (табл. 4).

Компоненты оборотных вод после отделения волокон остаются в фильтрате и часто далее исключатся из исследований. Для характеристики веществ фильтратов было проведено фильтрование суспензии на бумажном фильтре и через металлическую сетку. Фильтрат после фильтрования на плотном бумажном фильтре содержал только растворенные вещества, его значение ХПК равнялось 440 мг/л. Фильтрат, отделенный на сетке и содержащий растворенные и коллоидные вещества, имел значение ХПК 1610 мг/л. Следовательно, в суспензии скопа высоким остается содержание коллоидных веществ, способных значительно ухудшать водоотдачу.

Использование электронной микроскопии позволяет визуально отслеживать структурные изменения, происходящие с волокнами целлюлозы в результате химических, механических и ферментативных воздействий. Образцы волокон, как правило, сушат до воздушно-сухого состояния [3, 4], гораздо реже используют лиофильную сушку [5]. В данном исследовании методом электронной микроскопии было оценено состояние не только волокон, но и компонентов оборотных вод, содержащихся в суспензии скопа. Пробы к просмотру были подготовлены двумя методами: одну часть сушили до воздушно-сухого состояния, другую часть обезвоживали методом лиофильной сушки.

В суспензии скопа содержатся влажные первичные волокна, которые ранее высушиванию не подвергались. При сушке на воздухе даже при комнатной температуре происходят необратимые изменения структуры волокон. Физическая природа происходящих изменений связана с уплотнением клеточных стенок волокон, сжатием внутреннего канала и пор, перехода трубчатой формы волокон в ленточную, происходит ороговение волокон [6]. На рисунке 1 показаны отличия, которые имеют место при различных методах высушивания суспензии массы. На воздухе суспензия скопа высыхает в виде отливки, похожей на лист бумаги, что не позволяет в полной мере оценить особенности строения волокон (рис. 1а). Компоненты оборотной воды, содержащиеся в фильтрате, при таком методе высушивания утрачивают свои объемные параметры и в сухом виде также образуют плотную структуру в виде отливки (рис. 1б).

Структура волокон при лиофильном высушивании видна в объеме (рис. 1в и 1г), более четко она просматривается при условии использования золото-палладиевого напыления (рис. 1г). В скопе в небольшом количестве имеются ороговевшие волокна (рис. 1в), так как в композицию бумажной массы возвращается сухой оборотный брак.

Исследование суспензии скопа после лиофильной сушки показало (рис. 1д), что в ней крупные волокна окружены большим количеством очень мелких волокон, обрывков волокон, фрагментами первичной и вторичной мелочи. После отделения волокон на сетке часть веществ коллоидных размеров оказалась в фильтрате. При лиофильной сушке компоненты оборотной воды сохраняют свои структурные особенности (рис. 1е). Это в основном первичная и вторичная мелочь, размеры отдельных фрагментов которой соизмеримы с шириной волокон. Именно такие объемные структуры могут играть важную роль в формировании листа бумаги, участвовать в образовании межволоконных сил связи, но одновременно способны ухудшать водоотдачу суспензии массы.

Положительное влияние на скорость обезвоживания оказывает применение специфичных целлюлаз [7], в частности препарата Fiber Care D [8]. Считается, что главной причиной этого эффекта является деструкция коллоидных частиц и мелочи в оборотной воде, что снижает вязкость волокнистой массы. В эксперименте с пробой скопа после ферментативной обработки наблюдалось уменьшение длительности фильтрования более чем в два раза при расходе фермента 3 кг/т волокна (табл. 5). Выход осадка на фильтре после обработки уменьшился на 0,3\% при расходе фермента 1 кг/т волокна и на 1,4\% при увеличении расхода до 3 кг/т волокна.

Таблица 4. Фракционный состав волокон скопа и веществ фильтрата

\begin{tabular}{l|c|c|c|c|c|c}
\hline \multicolumn{1}{c|}{ Вид } & \multicolumn{7}{|c}{ Воссовая доля фракций волокон, \% } \\
\cline { 2 - 7 } & $0,2-0,3 \mathrm{Mм}$ & $0,3-0,6 \mathrm{Mм}$ & $0,6-1,2 \mathrm{Mм}$ & $1,2-2,4 \mathrm{Mм}$ & $2,4-5,0 \mathrm{Mм}$ & $>5,0$ мм \\
\hline Скоп (суспензия) & 9,9 & 15,9 & 33,4 & 24,0 & 15,6 & 0,2 \\
Отделенное волокно & 11,1 & 17,2 & 32,5 & 23,9 & 15,3 & - \\
Вещества фильтрата & 58,0 & 33,2 & 5,4 & 2,8 & 0,8 & - \\
\hline
\end{tabular}




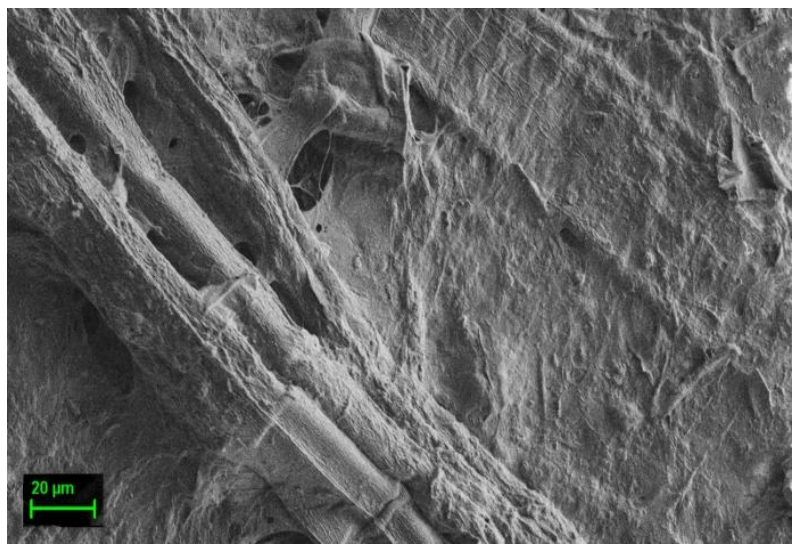

a
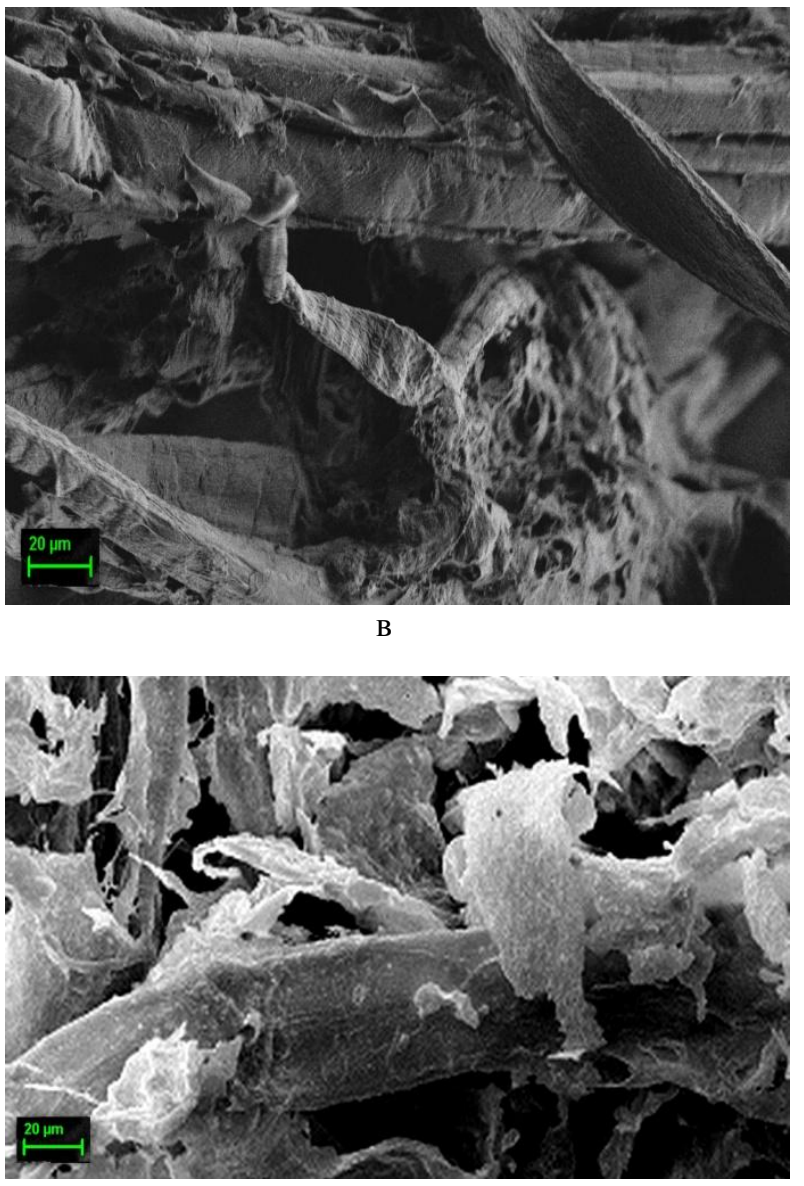

Д

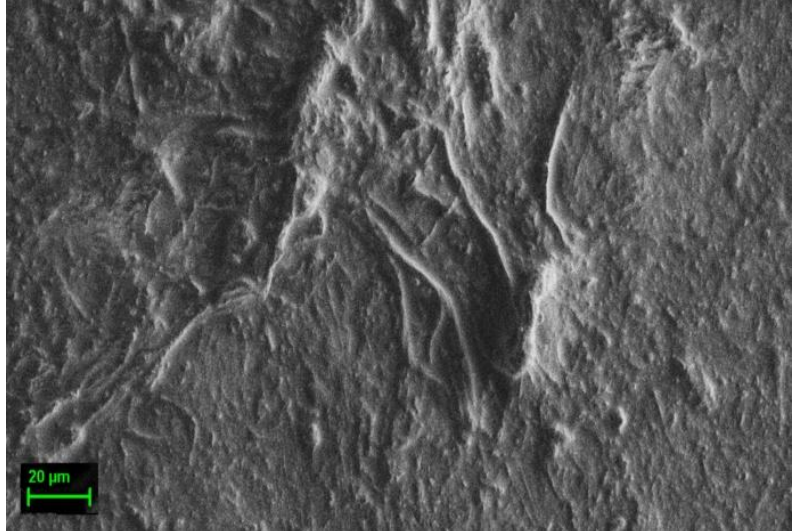

6
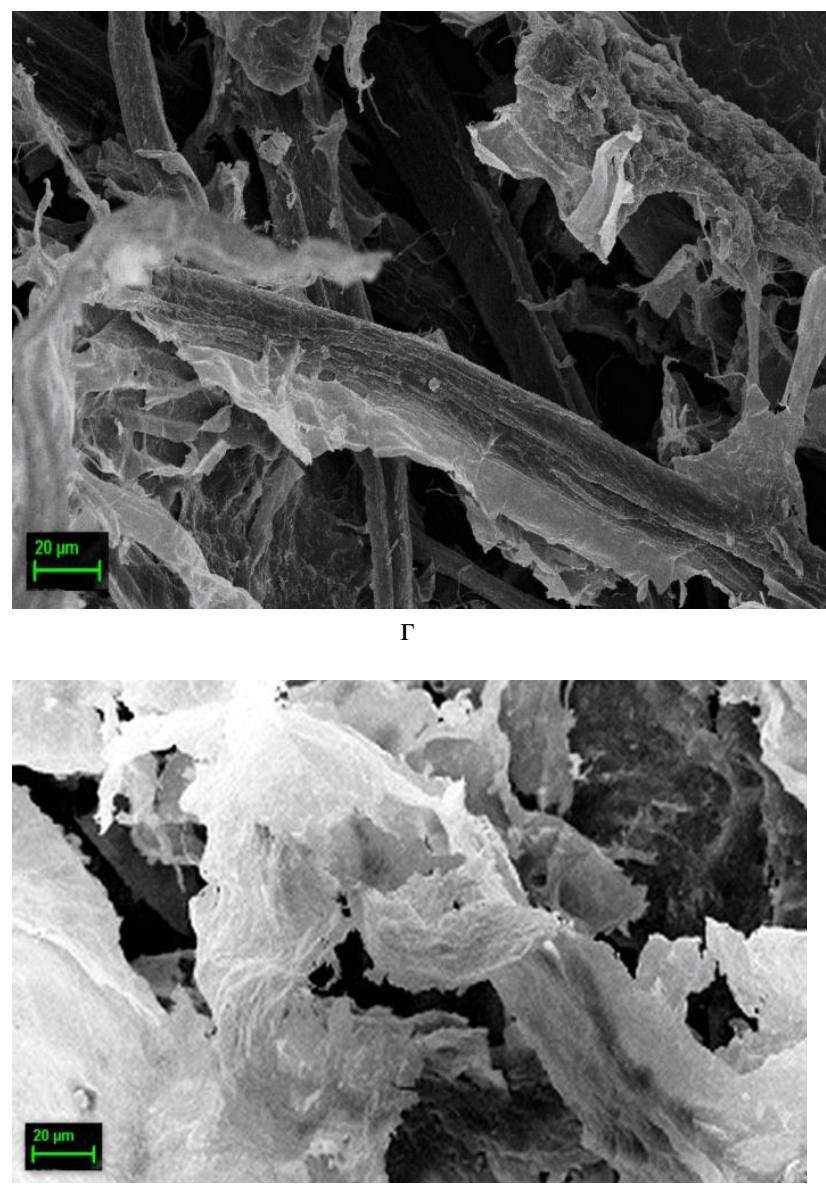

$\mathrm{e}$

Рис. 1. Фотографии образцов скопа, волокон и веществ фильтрата: а) скоп, высушенный на воздухе, б) вещества фильтрата, высушенные на воздухе, в) волокно, высушенное лиофильно, г) волокно, высушенное лиофильно и покрытое золотом, д) суспензия скопа, высушенная лиофильно, е) вещества фильтрата, высушенные лиофильно

Таблица 5. Выход осадка и продолжительность фильтрования в зависимости от расхода фермента на обработку скопа

\begin{tabular}{l|c|c|c}
\hline \multicolumn{1}{c|}{ Проба суспензии скопа } & $\begin{array}{c}\text { Расход фермента, } \\
\text { кг/т волокна }\end{array}$ & Выход осадка, \% & $\begin{array}{c}\text { Продолжительность } \\
\text { фильтрования, с }\end{array}$ \\
\hline Контрольная & - & 100,0 & 106 \\
Обработанная ферментом & 1 & 99,7 & 79 \\
Обработанная ферментом & 3 & 98,6 & 54 \\
\hline
\end{tabular}


Ферментативная обработка фракции волокна не дала результата с точки зрения улучшения обезвоживания. В экспериментах с пробами фильтратов, содержавших только растворенные и растворенные и коллоидные вещества, после обработки ферментом наблюдалось уменьшение времени фильтрования примерно в два раза. Количество осадка на бумажном фильтре в результате деструкции части веществ фильтратов по сравнению с контролем уменьшилось незначительно, всего на 2\%. Таким образом, обработка ферментом Fiber Care D позволяет существенно улучшить обезвоживающую способность скопа за счет воздействия фермента только на коллоидные и растворенные вещества без потери выхода волокна.

Поскольку уловленное волокно добавляется в композицию бумажной массы, было проверено, как его введение влияет на характеристики бумаги. Для этого приготовили отливки из смеси небеленой сульфатной хвойной целлюлозы и скопа, долю скопа в композиции массы задавали в количестве 5 и $10 \%$ от волокна (рис. 2).

Как видно из рисунка 2, основные показатели механической прочности при добавлении скопа в количестве 5\% от волокна практически равны показателям контрольного образца.
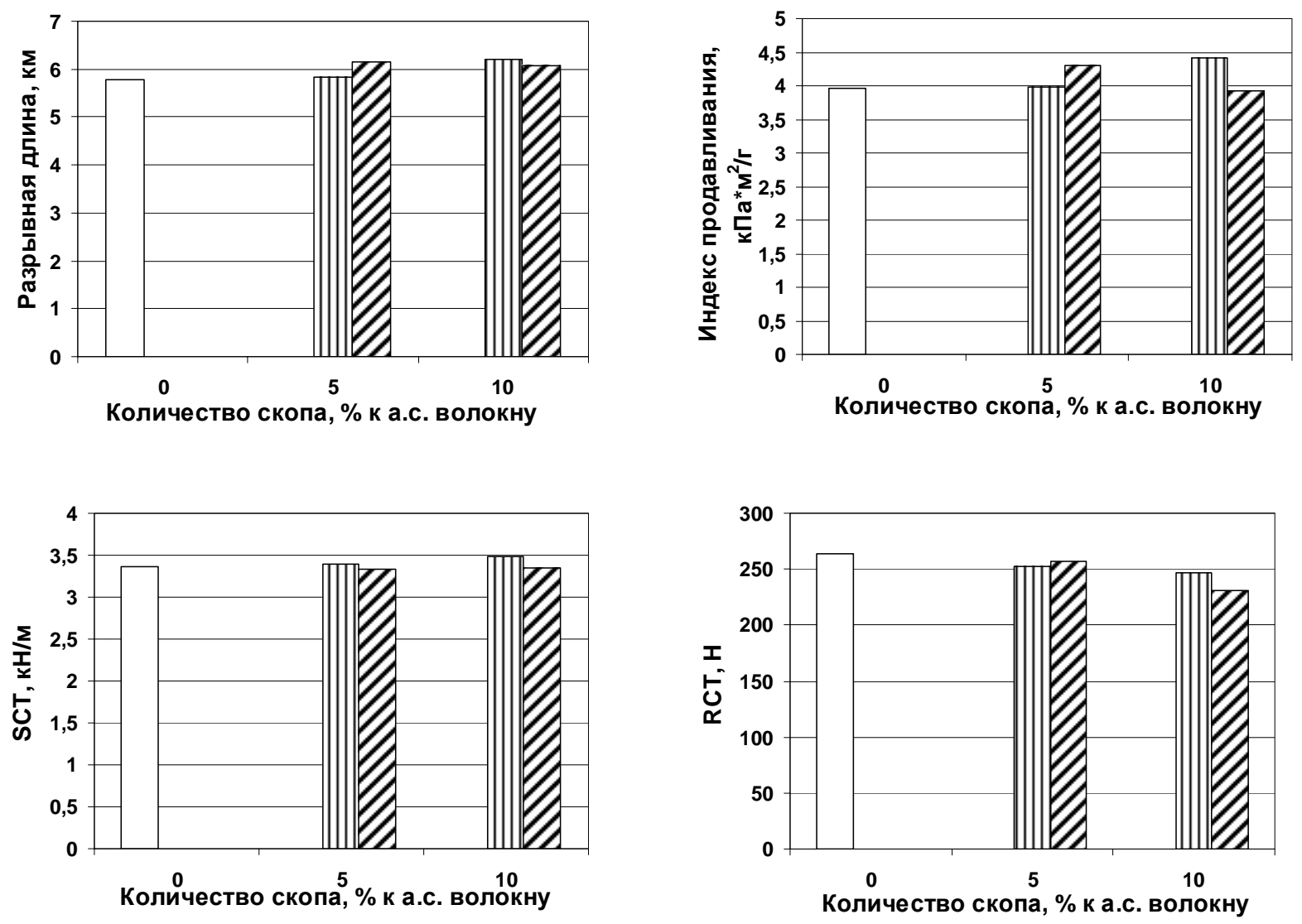

Рис. 2. Показатели механической прочности отливок бумаги, изготовленных из смеси небеленой сульфатной хвойной целлюлозы и скопа: $\square$ - контроль, фермента 3,0 кг/т

\section{Выводы}

1. Установлено, что в скопе, отделенном от оборотной воды флотацией, наблюдается высокое содержание фракции коротких волокон (мелочи).

2. Лиофильная сушка в сочетании с напылением золото-палладиевой смесью позволяет при исследовании методом электронной микроскопии выявить структурные особенности волокон скопа и компонентов оборотных вод.

3. Суспензия скопа содержит первичную и вторичную мелочь, размеры отдельных фрагментов которой соизмеримы с шириной волокон. Ухудшение водоотдачи скопа связано главным образом с накоплением мелочи и наличием в суспензии скопа коллоидных и растворенных веществ оборотной воды. 
4. Ферментативная обработка позволяет значительно улучшить обезвоживающую способность скопа без потери выхода волокна и снижения показателей прочности при возврате скопа в композицию бумажной массы.

\section{Список литературы}

1. Дулькин Д.А, Спиридонов В.А., Комаров В.И. Современное состояние и перспективы использования вторичного волокна из макулатуры в мировой и отечественной индустрии бумаги. Архангельск, 2007. 1118 с.

2. Backstrom M., Kolar M.-C., Htun M. Characterisation of fines from unbleached kraft pulps and their impact on sheet properties // Holzforschung. 2008. Vol. 62. Pp. 546-552.

3. Guan Y., Qian L., Xiao H., Zheng A., He B. Synthesis of a novel antimicrobial-modified starchand its adsorption on cellulose fibers: part II—adsorption behaviors of cationic starch on cellulose fibers // Cellulose. 2008. N15. Pp. 619-629.

4. Henriksson A., Gatenholm P. Surface properties of CTMP fibers modified with xylans // Cellulose. 2002. N9. Pp. 55-64.

5. Duchesne I., Hult E.-L., Mohlin U., Daniel G., Iversen T., Lennholm H. The influence of hemicellulose on fibril aggregation of kraft pulp fibres as revealed by FE-SEM and CP/MAS ${ }^{13} \mathrm{C}-\mathrm{NMR} / /$ Cellulose. 2001. N8. Pp. 103-111.

6. Фляте Д.М. Технология бумаги : учеб. для вузов. М., 1988. 440 с.

7. Петерсен Х. Применение ферментов в технологии переработки макулатуры // Современные научные основы и инновационные технологии бумажно-картонных материалов с использованием вторичного волокна из макулатуры : научные труды межд. науч.-техн. конференции. Караваево. 2006. С. 31-34.

8. Новожилов Е.В., Мартынов В.Ю., Крупенин И.С. Инновационные ферментные технологии для макулатурной массы // Особенности производства бумаги, картона и гофротары : матер. международной конференции. Киев, 2009. С. 45-48. 
Novozhilov E.V., Chukhchin D.G., Belykh E.V., Porotova P.V., Varakin E.A., Tyshkunova I.V. FEATURE OF FINES, FORMED BY THE LOCAL FIBER-CLEANING WASTEWATER

Northern (Arctic) Federal University named after M.V. Lomonosov, Severnaya Dvina Emb., 17, Arkhangelsk, 163002

(Russia),e-mail: biotech@agtu.ru

The composition and properties of the fines, the resulting wastewater treatment paper mill by flotation, shows the characteristics of the selected fibers fines and substances filtrates, the possibility of improving the dewatering capacity osprey by its enzymatic treatment, evaluated the effect of adding an fines on the strength of cast paper.

Keywords: fines, fiber, flotation, fractionation, electron microscopy, the dewatering capacity, cellulase.

\section{References}

1. Dul'kin D.A, Spiridonov V.A., Komarov V.I. Sovremennoe sostoianie i perspektivy ispol'zovaniia vtorichnogo volokna iz makulatury v mirovoi $i$ otechestvennoi industrii bumagi. [Current state and prospects for the use of recycled fiber from waste paper in the global and domestic industry paper]. Arkhangelsk, 2007, 1118 p. (in Russ.).

2. Backstrom M., Kolar M.-C., Htun M. Holzforschung, 2008, vol. 62, pp. 546-552.

3. Guan Y., Qian L., Xiao H., Zheng A., He B. Cellulose, 2008, no. 15, pp. 619-629.

4. Henriksson A., Gatenholm P. Cellulose, 2002, no. 9, pp. 55-64.

5. Duchesne I., Hult E.-L., Mohlin U., Daniel G., Iversen T., Lennholm H. Cellulose, 2001, no. 8, pp. 103-111.

6. Fliate D.M. Tekhnologiia bumagi. [Paper technology]. Moscow, 1988, 440 p. (in Russ.).

7. Petersen Kh. Sovremennye nauchnye osnovy $i$ innovatsionnye tekhnologii bumazhno-kartonnykh materialov s ispol'zovaniem vtorichnogo volokna iz makulatury: nauchnye trudy Mezhd. nauchno-tekhn. konferentsii. [Modern scientific foundations and innovative technology of paper and cardboard materials using recycled fiber from waste paper: Scientific Proceedings of the International scientific and technical conference.]. Karavaevo, 2006, pp. 31-34. (in Russ.).

8. Novozhilov E.V., Martynov V.Iu., Krupenin I.S. Osobennosti proizvodstva bumagi, kartona i gofrotary: mater. mezhdunarodnoi konferentsii. [Features of the production of paper, cardboard and corrugated packaging: proceedings of the international conference]. Kiev, 2009, pp. 45-48. (in Russ.).

Received November 25, 2013

\footnotetext{
*Corresponding author.
} 